\title{
El principio de mérito para el acceso a la función pública, especial referencia a los cargos de elección popular.
}

The principle of merit for access to the public function, special reference to popular election charges.

\author{
Wilson Enrique Vanegas Pérez ${ }^{1}$
}

\begin{abstract}
RESUMEN
En el presente artículo de reflexión se analizará la importancia del Principio constitucional de mérito, proponiendo que se cumplan unos requisitos de idoneidad para acceder a cargos de elección observado desde el Enfoque del argumento a fortiori, asimismo se realizará un parangón con las normas de Chile. El presente Artículo es de Corte descriptivo, y de tipo metodológico deductivo.
\end{abstract}

\section{Palabras claves:}

principio de Merito, cargos de elección popular, argumentación a Fortiori, Función pública.

\begin{abstract}
.
In this article of reflection, we will analyze the importance of the constitutional principle of merit, proposing that fulfillment requirements are met to access election positions observed from the Focus of the argument a fortiori, also will be made a comparison with laws of Chile. The present article is of Descriptive section, and of deductive methodological type.
\end{abstract}

\section{Keywords:}

Merit principle, popular election charges, Fortiori argumentation. Public function.

\footnotetext{
${ }^{1}$ Abogado. Especialista en derecho constitucional de la Corporación Universitaria Americana. Asesor, consultor y litigante en derecho constitucional y político. Correo: wilzon29@hotmail.es
}

Recibido: 8 de marzo de 2019. Aprobado: 28 de mayo de 2019. 


\section{Introducción.}

En el siguiente texto que corresponde a un artículo de corte reflexivo, se intentará sustentar la necesidad de implementar una serie de requisitos o condiciones mínimas en materia de formación académica para acceder a cargos de elección popular, teniendo en cuenta que estos cargos - según algunos puntos vista, incluyendo el nuestro - requieren de algún tipo de formación para ser desempeñados con idoneidad.

Una iniciativa en este sentido fue propuesta en Colombia en el año 2016 por un represente a la cámara por el departamento del Vaupés, Norbey Marulanda Muñoz, quien radicó un proyecto de acto legislativo que busca aumentar los requisitos académicos de quienes se postulan a cargos de elección popular, y acreditar un título de formación universitaria o profesional en una institución reconocida por el Ministerio de Educación Nacional, además de los ya establecidos en la constitución. (El Nuevo siglo, 2016).

En el mismo sentido, Quintanilla (2003) manifiesta que parece conveniente que las personas que son elegidas para dirigir el destino de la patria "deben estar lo suficientemente preparados en cuanto a integridad personal y educación".

Bien expresó Orlando Caballero, en su libro los 7 pecados capitales políticos (2016, pág.71), "Deviene en reprochable e imperdonable, cuando el actor político con 
sus acciones públicas da lugar al aumento de las vicisitudes sociales que golpean a los más necesitados, en particular como a la sociedad en general, por ignorancia supina o falta de conocimiento o imprevisión."

\section{Metodología.}

El presente Artículo es de Corte descriptivo, toda vez que se analiza un fenómeno jurídico actual que es la falta de exigencia de formación académica para determinados cargos de elección popular, sola desde una perspectiva de las características, contenido y descripción de las normas y teorías doctrinarias al respecto, sin entrar a indagar por aspectos de causalidad o efectos. El método es deductivo, puesto que de disposiciones normativas generales, se llegaran a conclusiones particulares. El paradigma es el crítico social, en el sentido que se plantea una redefinición del statu quo sobre requisitos para acceso a cargos públicos.

\section{Resultados.}

1. Principio de mérito para el ejercicio de la función pública y el liderazgo político.

Según la ley LEY 909 DE 2004 en su Artículo 2ºstablece los Principios de la función pública, en la cual desarrolla en pleno la igualdad, el mérito, la moralidad, eficacia, economía, imparcialidad, transparencia, celeridad y publicidad, resaltando las 
calidades y capacidades profesionales de los individuos que desempeñen un rol importante en la función pública.

Es necesario insistir siempre en que el político y el funcionario del Estado están en ese lugar al servicio de la gente. Sea que fueron elegidos por el pueblo o que ocupen un cargo de responsabilidad en la estructura del Estado, su función es permitir que las estructuras trabajen en beneficio de la población, especialmente de los más postergados. Andiñach, Pablo R (2001, p,40).

Los funcionarios públicos y el actor Político, ejercen un liderazgo bajo la lupa de la eficacia, eficiencia y capacidad en la toma de decisiones, ya que su desempeño se refleja para bien o para mal, en el progreso de una "empresa" o del Estado, Por tanto, estamos obligados a crear nuevas alternativas de provecho plural, innovando en conocimiento y en ciencias políticas, sin ser abusivos del poder (respecto abusos en aspecto contractual y otros, Álvarez, 2009)

Así lo determina Ramírez - Aluja (2012, citado por López Santos, 2016) cuando estima que la innovación permite que las administraciones públicas mejoren la prestación de servicios y fortalezcan el vínculo entre el gobierno y otros actores, como pueden ser la ONG, las empresas privadas o la sociedad civil. 
Los procesos de innovación atraviesan por cambios estructurales que favorecen la apertura de espacios de participación, modificaciones en las rutinas de prestación de servicios, reformas en políticas públicas y adopción de tecnologías de información y comunicación.

Por consiguiente, tanto el funcionario público, como el privado, deben aunar sus labores como si se tratara de buscar el mismo Fin, en aras de acelerar el progreso de un País, Departamento, Municipio Etc. Siendo obligatorio entonces, que los dirigentes políticos estén capacitados para bien conducir las riendas de las instituciones ocupadas por ellos, y visionar competir nacional e internacionalmente con otras potencias, queriendo ampliar su territorio industrial y afianzar una economía sólida y sostenible.

Según datos de la ONU ampliamente citados, 51 de las 100 mayores economías del mundo son empresas, no países. A medida que el poder va pasando de los estados nacionales a las empresas, los grupos de interés y las comunidades de todo el mundo ya no esperan únicamente de los líderes empresariales que se limiten a cumplir las leyes y normativas y a incrementar el valor para los accionistas. Por el contrario, existe un consenso generalizado sobre, por ejemplo, el hecho de que las corporaciones multinacionales y sus dirigentes tienen los medios, el poder y en última instancia la responsabilidad de actuar como agentes del beneficio mundial y no de la miseria mundial, es decir, la responsabilidad de contribuir a resolver algunos de los problemas 
más acuciantes en el mundo, tales como el VIH/sida, el calentamiento global, la pobreza y el hambre. (Nicola M.; Maak 2010: 58).

En el ser y el deber ser de los actores Públicos y políticos, se pregona un comportamiento y desempeño idóneo en sus funciones, que en conjunto dan buenos resultados, agregando valores y buena actitud en el ejercicio Funcional.

Tal cual lo expresa Ramos (2000, pág. 121). "Valor y actitud forman un conjunto, una configuración estímulo respuesta y son los elementos dinamizadores del comportamiento humano".

\section{Una propuesta sobre los requisitos de idoneidad para acceder a cargos de} elección popular. Enfoque desde el argumento a fortiori.

Caballero D (2016) expresa que se requiere de un político capacitado para que pueda obrar con diligencia.

En el ejercicio de la función pública, y todo lo que este principio representa, denotan un alto grado de responsabilidad administrativa y civil, en la toma de decisiones, y que, si a este le faltare capacidad a la hora de ejecutar sus funciones, los ciudadanos administrados serían los más afectados. 
Por tanto, me es menester presentarles a ponderación, que aquellos aspirantes que sean elegidos popularmente a través del voto, y finalmente ocupen los cargos públicos temporalmente, hasta ser posiblemente electos en los próximos comicios, deban reunir algunos requisitos académicos de idoneidad para acceder a dichas Funciones.

Recurro en esta disertación al argumento $A$ fortiori. (A fortiori es una locución latina que significa 'con mayor motivo'), entonces, si en Colombia, el proceso de selección que hace la Comisión Nacional Del Servicio Civil CNSC, para ocupar los cargos públicos vacantes, promocionado en su página virtual y, evaluando a los admitidos, su nivel de experiencia y educación a través de una Universidad Certificada, para así, fortalecer los principios de Mérito, Igualdad, Capacidad, y demás Principios Constitucionales, a la hora de ejercer.

Entonces, "Con mayor motivo", se lo debemos exigir a los Presidentes, Congresistas, Gobernadores, Diputados, Alcaldes, Concejales y Ediles.

Quintanilla, A. (2003) señala que existen experiencias exitosas en Japón y Francia, en donde las autoridades deben pasar por una escuela de educación política para obtener el cargo. "No sé si en América Latina pueda funcionar, pero creo que con el tiempo se puede lograr", refirió la autoridad universitaria. 


\section{Análisis del caso Colombo - Chileno en materia de requisitos exigidos a los aspirantes a ser elegidos popularmente.}

En Colombia los Ciudadanos tienen garantizados en el Art 40 de la Carta Magna,

el derecho a elegir y a ser elegido a través del voto popular, entre otros derechos taxativamente ahí descritos, y a ocupar el cargo Público para el cual fueron electos. Pero llama la atención que aquellos que aspiran ser elegidos electoralmente a través del sufragio, no se les exige ningún requisito académico.

Es claro que la competencia en la función pública, juega un papel importante en el Estado, en pro de beneficiar a la sociedad, ya que ésta garantiza el desempeño idóneo y eficiente en la toma de decisiones, y en la administración de los recursos.

"Ya que el actor político debe ser diligente en la toma de decisiones, en cuanto a la solvencia intelectual que requiere el conocimiento necesario para minimizar la posibilidad del yerro político, que vulnera los derechos colectivos". Caballero D (2016). 
Ya que estos actores al momento de querer diseñar las políticas públicas, deben tener la capacidad intelectual y asertiva para contrarrestar los fenómenos sociales que se presenten o prevenirlos en lo mejor de los casos, y no actuar movido por las emociones o impulsos influenciados por los medios de comunicación cuando emiten la noticia criminal.

Muñoz Soro (2007), señala, que los políticos son viscerales no intelectuales. Según Amando de Miguel, el intelectual es quien espera su turno en la antesala del poder (10). Se ha extinguido para siempre la figura del intelectual «orgánico», vinculado directamente a los partidos políticos, probablemente porque la dependencia ha pasado a ser inversa, a favor de los «intelectuales colectivos» — periódicos, revistas, internet, canales de radio o televisión- organizados en poderes mediáticos cada vez más poderosos y autónomos. En este texto se considerará como «intelectuales» a todos aquellos creadores de opinión en el espacio público y mediático, con una intencionalidad política explícitamente asumida.

En otra esfera, avocamos a la Constitución Chilena en sus artículos 48,50, y la ley 18.695, ya que estas, exigen a los que aspiran ser elegidos popularmente como Alcaldes, Diputados y Senadores de Chile, el requisito de haber cursado la enseñanza media o equivalente. 
Corolario, esta Constitución Chilena, es la única en Latinoamérica que solicita tales requisitos a sus gobernantes.

\section{Conclusiones.}

El hilo conductor de este Artículo ha sido la idea de que la calidad de los políticos afecta a la calidad de la política estatal, cuyo carácter es multidimensional. En la medida en que el político de hoy debe ser profesional, teniendo en consideración que satisfacen en mayor o menor grado los requisitos mínimos de un político de calidad. (Alcántara Sáez, 2013).

En este escenario se pone especial énfasis en la parte formativa de los políticos, un aspecto descuidado por la academia y por nuestra constitución, ya necesitamos políticos con fundamentos teóricos prácticos, basado en la ciencia y tecnología partiendo de ideas innovadoras cambiantes, creando conocimientos científicos y haciendo de ella un verdadera identidad filosófica de un político que está a la vanguardia del mundo.

El futuro de Colombia deviene en buen augurio, si logramos deprecar un pensar unísono, en aras de contribuir al progreso y profesionalización de los dirigentes políticos que ejercen funciones de alto compromiso y responsabilidad con la sociedad y el 
desarrollo del País, sobre todo en lo educativo, que es sin duda el mayor aporte que le hacemos al Estado.

- En conclusión, si en Colombia los proceso de selección que hace la Comisión Nacional Del Servicio Civil CNSC, para ocupar los cargos públicos vacantes, promocionado en su página virtual y, evaluando a los admitidos, su nivel de experiencia y educación a través de una Universidad Certificada, para así, fortalecer los principios de Mérito, Igualdad, Capacidad, y demás Principios Constitucionales, a la hora de ejercer.

Entonces, A fortiori "Con mayor motivo", se lo debemos exigir a los Presidentes, Congresistas, Gobernadores, Diputados, Alcaldes, Concejales y Ediles.

\section{Referencias.}

Alcántara Sáez, M. (2013) De políticos y política: profesionalización y calidad en el ejercicio público. En Revista Perfiles latinoamericano. Enero-Junio.

Alvarez Estrada, J. (2009) (1). La libertad contractual del consumidor en Colombia: ¿mito o realidad? contratos de adhesión condiciones generales del contrato-cláusulas abusivas. $\quad$ Erg@omnes, $11(1), \quad 165$. https://doi.org/https://doi.org/10.22519/22157379.241

Andiñach, P. R. (2001) Para una ética de la función pública Invenio, vol. 4, núm. 6, junio, 2001, pp. 37-42 Universidad del Centro Educativo Latinoamericano Rosario, Argentina.

Caballero, A. (2003). Los siete pilares del toreo. Espasa-Calpe. 
Constitución Chilena en sus artículos 48,50, y la ley 18.695

El nuevo siglo, (2016), represente a la cámara por el departamento del Vaupés, Norbey Marulanda Muñoz, quien radicó un proyecto de acto legislativo que busca aumentar los requisitos.

Muñoz Soro, J. (2007) Historia y política: Ideas, procesos y movimientos sociales, ISSN 15750361, № 18, , pág. 132.

Ley 909 DE 2004 en su Artículo $2^{\circ}$

Quintanilla, A. (2003). El lenguaje de la intimidad. Sobre la constitución intersubjetiva de las emociones. Alfonso Flórez, Magdalena Holguín y Raúl Meléndez (comps.) Del Espejo a las Herramientas. Ensayos sobre el pensamiento de Wittgenstein. Bogotá: Siglo del Hombre Editores.

Nicola M.; Maak, T. (2010) Desarrollando líderes globales responsables Universia Business Review, núm. 27, 2010, pp. 56-69 Portal Universia S.A. Madrid, España

Ramírez-Alujas, Álvaro V. y César Cruz-Rubio (2012). "¿Políticas públicas abiertas: Hacia la definición y análisis de los diseños políticos bajo los principios del gobierno abierto". Revista Buen Gobierno №13. 